\title{
FORMULASI DAN UJI ANTIBAKTERI SEDIAAN MASKER GEL PEEL-OFF EKSTRAK ETANOL DAUN ALPUKAT (Persea americana Mill.) TERHADAP BAKTERI Staphylococcus epidermidis SEBAGAI ANTIJERAWAT
}

\author{
Esterlina A. Puluh ${ }^{1)}$, Hosea Jaya Edy ${ }^{1)}$, Jainer Pasca Siampa ${ }^{1)}$ \\ 1) Program Studi Farmasi FMIPA UNSRAT Manado, 95115
}

\begin{abstract}
Avocado leaves contain the compounds such as saponins, alkaloids, flavonoids, polyphenols, and quercetin which are as antibacterial properties. This study aims to obtain the best concentration of the formula of peel off gel mask preparation of avocado leaf ethanol extract (Persea americana Mill.) Based on antibacterial activity test and prove the quality preparation based on the test parameters of physical properties, physical stability and sterility. This study used a laboratory experimental methods, the formula for the preparation of avocado leaf extract peel off gel mask was made with a concentration variation of $0.1 \% ; 0.15 \% ; 0.2 \% ; 0.25 \%$ and $0.3 \%$. Avocado leaf extract is obtained by maceration using $96 \%$ of ethanol solvent. The largest diameter of inhibition zone of antibacterial testing with wells method is at a concentration of $0.3 \%$ with a diameter of the inhibition zone $3 \mathrm{~mm} \pm 0.32$ and the ability of inhibition is categorized as weak. The physical test and the stability of the preparation meet the evaluation parameters of the physical preparation before storage, but after storage the preparation does not meet the test requirements when drying. It can be concluded that the preparation of the extract of avocado leaf peel off gel mask meets the physical test parameters, is stable and has weak antibacterial activity.
\end{abstract}

Keywords: Avocado Leaf (Persea americana Mill.), Peel off mask, Antibacterial, Sterility Test.

\begin{abstract}
ABSTRAK
Daun Alpukat memiliki kandungan antara lain saponin, alkaloid, flavonoid, polifenol, quersetin yang bersifat sebagai antibakteri. Penelitian ini bertujuan untuk mendapatkan konsentrasi terbaik dari formula sediaan masker gel peel off ekstrak etanol daun alpukat (Persea americana Mill.) berdasarkan uji aktivitas antibakteri serta membuktikan sediaan yang berkualitas berdasarkan parameter uji sifat fisik, stabilitas fisik dan sterilitas. Penelitian ini menggunakan metode ekperimental laboratorium, formula sediaan masker gel peel off ekstrak daun Alpukat dibuat dengan variasi konsentrasi $0,1 \% ; 0,15 \% ; 0,2 \% ; 0,25 \%$ dan 0,3\%. Ekstrak tanaman daun alpukat diperoleh dengan cara maserasi menggunakan pelarut etanol 96\%. Pengujian antibakteri dengan metode sumuran diameter zona hambat yang paling besar yaitu pada konsentrasi $0,3 \%$ dengan diameter zona hambat $3 \mathrm{~mm} \pm 0,32$ dan kemampuan daya hambat dikategorikan lemah. Pada uji fisik dan stabilitas sediaan memenuhi parameter evaluasi sediaan fisik sebelum penyimpanan, tapi setelah penyimpanan sediaan tidak memenuhi persyaratan uji waktu mengering. Dapat disimpulkan bahwa sediaan masker gel peel off ekstrak etanol daun alpukat memenuhi parameter uji fisik, stabil dan memiliki aktivitas antibakteri yang lemah.
\end{abstract}

Kata kunci: Daun Alpukat (Persea americana Mill.), Masker peel off, Antibakteri, Uji Sterilitas. 


\section{PENDAHULUAN}

Penyakit kulit dapat menyerang siapa saja dan dapat menyerang pada bagian tubuh mana pun. Penyakit kulit dapat disebabkan oleh beberapa faktor seperti lingkungan dan kebiasaan sehari-hari yang buruk, perubahan iklim, virus, bakteri, alergi, daya tahan tubuh dan lain-lain (Pardiansyah, 2015). Penyakit kulit yang sering diderita adalah jerawat.

Jerawat biasanya muncul pada permukaan kulit wajah, leher, dada dan pungggung pada saat kelenjar minyak pada kulit terlalu aktif sehingga pori-pori kulit akan tersumbat oleh timbunan lemak yang berlebihan. Jika timbunan itu bercampur dengan keringat, debu dan kotoran lain, maka akan menyebabkan timbunan lemak dan bintik hitam di atasnya yang disebut komedo (Djajadisastra et al., 2009). Salah satu pengobatan dari bahan alam untuk jerawat adalah daun alpukat (Persea americana Mill.).

Kandungan daun alpukat antara lain saponin, alkaloid, flavonoid, polifenol, quersetin yang bersifat antiradang dan antibakteri (Cushnie and Lamb, 2005). Penelitian terdahulu menyatakan bahwa kandungan flavonoid yang terdapat dalam daun alpukat (Persea americana Mill.) mempunyai aktivitas sebagai antifungi, antiviral dan antibakteri (Christianto, dkk., 2012). Berdasarkan hasil uji Konsentrasi Hambatan Minimal (KHM) ekstrak daun alpukat terhadap pertumbuhan bakteri Staphylococcus epidermidis pada konsentrasi $0,2 \%$ dengan rerata diameter zona hambat sebesar 0,50 mm (Yunikasari, 2016).

Kosmetik wajah dapat diperoleh dalam berbagai bentuk sediaan, salah satunya dalam bentuk masker wajah gel peel off (Vieira, dkk., 2009). Masker wajah merupakan kosmetik perawatan kecantikan yang sangat popular untuk meningkatkan kualitas kulit (Yeom, dkk., 2011).

Pada penelitian ini, peneliti akan melakukan pembuatan formulasi sediaan masker gel peel off ekstrak etanol daun alpukat (Persea americana Mill) sehingga mendapatkan hasil yang baik, efektif, stabil, dan steril.

\section{METODOLOGI PENELITIAN Waktu dan Tempat Penelitian}

Penelitian ini dilaksanakan pada bulan Mei 2019- Agustus 2019 di Laboratorium Teknologi Farmasi, Program Studi Farmasi Fakultas Matematika dan Ilmu Pengetahuan Alam Universitas Sam Ratulangi.

\section{Bentuk Penelitian}

Penelitian ini adalah penelitian secara eksperimental laboratorium untuk mendapatkan formula optimum sediaan masker gel peel off ekstrak etanol Daun Alpukat (Persea americana Mill.).

\section{Alat dan Bahan \\ Alat \\ Alat-alat yang digunakan dalam penelitian ini adalah peralatan gelas, kertas saring, corong, oven, batang pengaduk, $\mathrm{pH}$ meter, timbangan analitik, inkubator $\left(\right.$ EcoCell $\left.^{\circledR}\right)$, pemberat, plat kaca, penggaris, mikropipet, dan cawan petri, mixer, jangka sorong, LAF, autoclave, dan lemari pendingin.}

\section{Bahan}

Simplisia Daun Alpukat, etanol 96\%, PVA, HPMC, TEA, Gliserin, Aquadest, Nutrien Agar (NA), bakteri Staphylococcus epidermidis ATCC 12228, larutan $\mathrm{BaCl}_{2} 1 \%$, 
$1,175 \%$, larutan $\mathrm{H}_{2} \mathrm{SO}_{4} 1 \%$, larutan $\mathrm{NaCl}$ $0,9 \%$, dan gel spot “Acnes ${ }^{\circledR}$ ".

\section{Prosedur Penelitian}

\section{Pengambilan Sampel}

Pengambilan sampel daun Alpukat (Persea americana Mill.) di kecamatan Girian, kota Bitung.

\section{Identifikasi Sampel}

Identifikasi tanaman dilakukan di Laboratorium Taksonomi Tumbuhan, Jurusan Biologi, Fakultas Matematika dan Ilmu Pengetahuan Alam, Universitas Sam Ratulangi Manado.

\section{Ekstraksi}

Pengambilan sampel daun Alpukat (Persea americana Mill.) di kecamatan Girian, kota Bitung. Sampel dipreparasi dan daun yang terkumpul dicuci bersih dengan air mengalir untuk menghilangkan pengotor. Pengeringan daun dilakukan di dalam oven dengan suhu $40^{\circ} \mathrm{C}$ sampai daun kering sempurna. Daun kering kemudian diserbuk lalu diayak menggunakan ayakan tepung dan dilanjutkan dengan proses perendaman (Edy, dkk., 2016).

Proses ekstraksi serbuk daun Alpukat menggunakan sistem metode maserasi. Serbuk daun Alpukat ditimbang sebanyak $400 \mathrm{~g}$ dan dimasukkan dalam toples lalu ditambahkan pelarut etanol $96 \%$ sebanyak $2000 \mathrm{~mL}$ didiamkan selama 3 hari sambil sesekali diaduk. Setelah 3 hari disaring dengan menggunakan kertas saring dan menghasilkan filtrat 1 dan debris 1 . Debris 1 yang ada kemudian direndam lagi (remaserasi) dengan pelarut yang sama selama 2 hari sambil sesekali diaduk. Setelah
2 hari, sampel disaring sehingga menghasilkan filtrat 2 dan debris 2 . Filtrat 1 dan filtrat 2 dicampurkan menjadi satu lalu dievaporasi menggunakan rotary evaporator sehingga diperoleh ekstrak kental lalu kemudian dikerok dan di masukkan ke dalam pot salep dan di timbang.

\section{Formulasi}

Tabel 1. Formulasi sediaan masker peel off ekstrak etanol daun Alpukat (Persea americana Mill.)

\begin{tabular}{llllll}
\hline Bahan & \multicolumn{5}{c}{ Formula (\%b/v) } \\
& $\mathrm{F}_{1}$ & $\mathrm{~F}_{2}$ & $\mathrm{~F}_{3}$ & $\mathrm{~F}_{4}$ & $\mathrm{~F}_{5}$ \\
& & & & & \\
$\begin{array}{l}\text { Ekstrak } \\
\text { etanol }\end{array}$ & 0,1 & 0,15 & 0,2 & 0, & $0,3 \%$ \\
$\begin{array}{l}\text { Daun } \\
\text { Alpukat }\end{array}$ & & & $\%$ & $25 \%$ & \\
PVA & 10 & 10 & 10 & 10 & 10 \\
HPMC & 1 & 1 & 1 & 1 & 1 \\
$\begin{array}{l}\text { Gliserin } \\
\text { TEA }\end{array}$ & 12 & 12 & 12 & 12 & 12 \\
$\begin{array}{l}\text { Aquade } \\
\text { stilata }\end{array}$ & 100 & 0,15 & 0,15 & 0,15 & 0,15 \\
\end{tabular}

Terlebih dahulu dikembangkan HPMC dalam aquadest dingin dengan cara ditaburkan sedikit demi sedikit dan didiamkan \pm 24 jam hingga mengembang sempurna. PVA dikembangkan dalam aquadest menggunakan mixer. Kemudian, ditambahkan gliserin, yang telah dilarutkan dalam aquadestilata panas, HPMC, serta TEA secara berturut-turut ke dalam massa PVA, diaduk hingga homogen menggunakan mixer. Lalu disterilkan dalam autoklaf pada suhu $121^{\circ} \mathrm{C}$ dengan tekanan 1 atm selama 15 menit. Setelah itu ditambahkan ekstrak yang telah diencerkan dalam aquadest. Lalu diaduk hingga homogen dan dilakukan hal yang sama pada ekstrak yang lain. 


\section{Pengujian Antibakteri Sterilisasi Alat}

Alat-alat yang akan digunakan dalam penelitian aktivitas antibakteri ini dicuci bersih menggunakan sabun, kemudian dikeringkan dan setelah kering dibungkus dengan aluminium foil. Setelah itu disterilkan terlebih dahulu dengan menggunakan autoklaf pada suhu $121{ }^{\circ} \mathrm{C}$ tekanan 1 atm selama 15 menit, pinset, jarum ose dipijarkan diatas api bunsen dan media disterilkan di autoklaf pada suhu $121{ }^{\circ} \mathrm{C}$ tekanan 1 atm selama 15 menit (Ortez, 2005).

\section{Pembuatan Media dasar}

Nutrien Agar (NA) sebanyak 2,52 g dilarutkan dalam $90 \mathrm{~mL}$ aquades $(28 \mathrm{~g} / 1000$ $\mathrm{mL}$ ) menggunakan Erlenmeyer. Langkah berikutnya dihomogenkan dengan stirer di atas penangas air sampai mendidih. Kemudian media yang sudah homogen disterilkan dalam autoklaf dengan suhu $121^{\circ} \mathrm{C}$ tekanan $1 \mathrm{~atm}$ selama 15 menit, selanjutnya didinginkan sampai suhu $\pm 45^{\circ}-50^{\circ} \mathrm{C}$. Media dasar ini digunakan untuk pembuatan media pengujian sebagai lapisan dasar.

\section{Pembuatan Media Pembenihan}

Nutrien Agar (NA) sebanyak 2,52 g dilarutkan dalam $90 \mathrm{~mL}$ aquades menggunakan erlenmeyer. Kemudian dihomogenkan dengan stirrer diatas penangas air sampai mendidih. Selanjutnya media yang sudah homogen kemudian disterilkan dalam autoklaf pada suhu $121^{\circ} \mathrm{C}$ tekanan 1 atm selama 15 menit, langkah selanjutnya didinginkan pada suhu $\pm 45^{\circ} \mathrm{C}-50^{\circ} \mathrm{C}$. Media pembenihan ini digunakan untuk pembuatan media pengujian sebagai lapisan kedua.

\section{Pembuatan Suspensi Uji Bakteri}

Bakteri uji pada media agar miring diambil dengan menggunakan kawat ose steril lalu disuspensikan ke dalam tabung yang berisi $10 \mathrm{~mL}$ larutan $\mathrm{NaCl} 0,9 \%$ dalam tabung reaksi kemudian dikocok hingga diperoleh larutan yang keruh. Kekeruhan ini dipakai sebagai standar kekeruhan suspensi bakteri uji.

\section{Pembuatan Media Pengujian}

Media uji dibuat dengan metode difusi agar dengan cara sumuran dengan 2 lapisan media agar dengan pengerjaan sebagai berikut:

1. Lapisan dasar dibuat dengan cara menuangkan masing-masing $15 \mathrm{~mL}$ NA ke dalam 3 cawan petri, selanjutnya dibiarkan memadat.

2. Setelah memadat, pada permukaan lapisan dasar ditanam 7 pencadang yang diatur jaraknya agar daerah pengamatan tidak bertumpu.

3. Suspensi bakteri dicampurkan ke dalam pembenihan NA.

4. Kemudian dituangkan $15 \mathrm{~mL}$ NA media pembenihan ke dalam masing-masing cawan petri.

5. Setelah lapisan kedua memadat, pecandang diangkat secara aseptik menggunakan pinset dari masing-masing cawan petri, sehingga terbentuk sumur-sumur yang akan digunakan dalam uji antibakteri.

\section{Pembuatan Kontrol Positif dan Kontrol Negatif}

Kontrol positif untuk pengujian aktivitas antibakteri ini menggunakan gel spot "Acnes ${ }^{\circledR, " ~ d a n ~ u n t u k ~ k o n t r o l ~ n e g a t i f ~}$ menggunakan basis masker peel-off.

\section{Uji Aktivitas Antibakteri}

1. Bahan uji sediaan masker peel-off ekstrak daun Alpukat dengan konsentrasi 0,1\%; $0,15 \% ; \quad 0,2 \% ; \quad 0,25 \%$ dan $0,3 \%$ dimasukkan pada sumur-sumur yang berbeda sebanyak 0,1 gram menggunakan sudip.

2. Basis masker gel digunakan sebagai kontrol negatif dimasukkan pada sumursumur sebanyak 0,1 gram menggunakan sudip. 
3. Gel spot "Acnes ${ }^{\circledR}$ " digunakan sebagai kontrol positif dimasukkan pada sumursumur sebanyak 0,1 gram menggunakan sudip.

4. Kemudian cawan petri diinkubasi dalam inkubator pada suhu $37^{\circ} \mathrm{C}$ selama 24 jam.

\section{Pengamatan dan Pengukuran}

Pengamatan dilakukan setelah $1 \times 24$ jam masa inkubasi. Daerah bening merupakan petunjuk kepekaan bakteri terhadap antibiotik atau bahan antibakteri lainnya yang digunakan sebagai bahan uji yang dinyatakan dengan lebar diameter zona hambat. Diameter zona hambat diukur dalam satuan millimeter (mm) menggunakan jangka sorong dengan cara diameter keseluruhan dikurangi diameter sumuran $7 \mathrm{~mm}$. Selanjutnya diameter zona hambat tersebut dikategorikan kekuuatan daya antibakteri sesuai dengan krteria kekuatan daya antibakteri menurut Davis and Stout.

\section{Evaluasi Sediaan}

\section{Uji Organoleptis}

Uji organoleptis dilakukan dengan mengamati perubahan-perubahan bentuk, warna, dan bau dari sediaan masker gel (Septiani, 2012).

\section{Uji pH}

Uji pH dilakukan dengan cara mencelupkan elektroda $\mathrm{pH}$ meter ke dalam setiap sediaan masker gel yang sebelumnya telah dilarutkan dengan aquadestilata. Setelah elektroda tercelup, nyalakan $\mathrm{pH}$ meter kemudian didiamkan hingga layar pada $\mathrm{pH}$ meter menunjukkan angka yang stabil (Septiani, 2012). pH sediaan yang memenuhi kriteria pH kulit yaitu dalam interval 4,5 - 6,5 (Tranggono dan Latifa, 2007).

\section{Uji Daya Sebar}

Sampel gel masker peel-off sebanyak 0,5gram diletakkan pada kaca transparan yang berdiameter $15 \mathrm{~cm}$, ditutup dengan kaca lainnya di atasnya dan dibiarkan selama \pm 1 menit. Diameter sebar gel diukur. Setelah itu, ditambahkan beban tambahan seberat $150 \mathrm{~g}$ dan didiamkan selama 1 menit lalu diukur diameter yang konstan (Rajalakshmi, $d k k$., 2009).

\section{Uji Daya Lekat}

Sebanyak 0,25 gram gel dioleskan pada plat kaca, kedua plat ditempelkan sampai menyatu. Gel diantara plat kaca ditekan dengan beban $1 \mathrm{~kg}$ selama 5 menit. Plat kaca yang saling menempel dipasang pada alat uji daya lekat dan dilepas dengan beban 80 gram, kemudian dicatat waktu saat kedua plat tersebut lepas. Replikasi dilakukan sebanyak tiga kali (Rahmawati, dkk., 2010). Persyaratan daya lekat yang baik untuk sediaan topikal adalah lebih dari 4 detik (Rachmalia, dkk., 2016).

\section{Uji Waktu Mengering}

Pengujian waktu mengering dengan cara mengoleskan $0,7 \quad \mathrm{~g}$ sediaan dan disebarkan di atas permukaan kaca dengan area seluas $5,0 \times 2,5 \mathrm{~cm}$ hingga terbentuk lapisan tipis seragam dengan tebal kurang lebih $1 \mathrm{~mm}$. Setelah kaca diolesi dengan masker gel peel-off, kemudian dimasukkan ke dalam oven pada temperatur $37 \pm 2{ }^{\circ} \mathrm{C}$. Sediaan dimonitor sampai pengeringan selesai (Priani, 2015). Pengujian waktu mengering ini dilakukan karena masker gel peel off diharapkan akan membentuk lapisan film 
PHARMACON- PROGRAM STUDI FARMASI, FMIPA, UNIVERSITAS SAM RATULANGI, Volume 8 Nomor 4 November 2019

dalam waktu tertentu setelah diaplikasikan (Sulastri., dkk, 2016).

\section{Uji Sterilitas}

Kabinet LAF dibersihkan menggunakan alkohol $70 \%$ dan didiamkan di bawah sinar UV selama 24 jam sebelum digunakan. Media agar dibuat dengan memanaskan 21 g Nutrien Agar (NA) dalam $750 \mathrm{~mL}$ akuades, di atas hotplate magnetic stirrer dengan bantuan stirrer. Media NA kemudian dituang ke dalam tabung-tabung reaksi untuk disterilisasi dalam autoklaf $\left(121^{\circ} \mathrm{C}, 1 \mathrm{~atm}, 15\right.$ menit). Setelah sterilisasi, media NA dituang ke cawan petri dan dibiarkan memadat. Sediaan yang telah selesai dibuat kemudian di-streak dengan ose pada media agar secara zig-zag. Masingmasing petri kemudian dibungkus dengan plastic wrap dan diinkubasi terbalik pada suhu $30-35^{\circ} \mathrm{C}$ selama 24 jam (Divadi dan Yuliani, 2015).

\section{Uji Stabilitas Fisik (cycling test)}

Uji stabilitas fisik pada penelitian ini menggunakan metode cycling test. Sediaan disimpan di tempat dengan suhu $5^{\circ} \pm 2^{\circ} \mathrm{C}$ selama 24 jam, setelah itu sediaan dimasukkan ke dalam oven dengan suhu $40 \pm$ $2^{\circ} \mathrm{C}$ selama $24 \mathrm{jam}$. Perlakuan tersebut disebut satu siklus. Perlakuan tersebut dilakukan selama 12 hari (6 siklus) dan setiap siklus diamati terjadinya perubahan fisik dari sediaan masker gel peel off (Organoleptis, $\mathrm{pH}$, daya sebar, daya lekat dan waktu mengering). Kemudian kondisi fisik sediaan (apakah ada pemisahan) dibandingkan selama percobaan dengan kondisi awal sediaan (Angela, 2012).

\section{HASIL DAN PEMBAHASAN}

Dalam penelitian ini pembuatan masker peel-off ekstrak etanol daun Alpukat mengunakan basis PVA (polivinil alkohol) sebagai plasticizer, Hidroksipropil Metilselulosa (HPMC) sebagai peningkat viskositas, gliserin sebagai humektan, TEA sebagai zat pengemulsi dan aquadest digunakan sebagai pelarut.

Sampel basah daun Alpukat diperoleh sebanyak 3,4 kg dan diperoleh sampel kering sebanyak 2,6 kg. Pengeringan ini bertujuan untuk untuk menurunkan kadar air dalam daun Alpukat. Pengurangan kadar air dalam sampel bertujuan agar proses enzimatik dimana kandungan kimia yang terkandung dalam bahan diubah menjadi produk lain atau dirusak oleh enzim. Tanda sampel yang sudah kering yaitu apabila ketika diremas menggunakan tangan sampel mudah dipatahkan. Mudah dipatahkannnya sampel ini menunjukkan bahwa sampel tersebut kandungan airnya kurang dari 10\% (Sitepu, 2010), pengeringan juga mencegah adanya bertumbuhnya kapang dan jamur sehingga sampel dapat disimpan dalam waktu yang lama. Kemudian menghasilkan serbuk simplisia sebanyak 400 gr. Pembuatan simplisia ini bertujuan untuk memperbesar luas permukaan sampel yang akan berinteraksi dengan pelarut sehinga senyawasenyawa yang ada dalam sampel dapat larut lebih banyak.

Ekstraksi yang dilakukakan pada penelitian ini menggunakan metode maserasi. Proses maserasi juga mempunyai keuntungan lain dari metode ekstraksi lainnya yaitu cara pengerjaannya yang sederhana dan peralatan yang mudah didapat, sederhana dan tidak memerlukan alat yang khusus dan juga metode maserasi dipilih karena merupakan 
metode yang paling umum digunakan dalam pembuatan ekstrak bahan alam. Pemilihan pelarut dalam ekstraksi merupakan salah satu faktor penting karena dapat mempengaruhi suatu keberhasilan ekstraksi. Pelarut yang digunakan dalam ekstraksi ini yaitu etanol 96\% menurut (Tiwari $d k k, 2011$ ), etanol merupakan pelarut yang bersifat universal dan selektif dalam melarutkan senyawa-senyawa kimia yang dinginkan dan lebih efisien dalam degradasi dinding sel yang bersifat non polar sehingga polifenol akan tersari lebih banyak. Ekstrak kental yang diperoleh selama proses maserasi yaitu sebanyak $43 \mathrm{~g}$.

Hasil penelitian yang didapat dari uji antibakteri terhadap sediaan masker gel peel off dengan konsentrasi $0,1 \% ; 0,15 \% ; 0,2 \%$; $0,25 \%$ dan $0.3 \%$ menujukkan bahwa lebih besar menghambat bakteri pada konsentrasi $0.3 \%$ dengan rerata daya hambat sebesar 3 $\mathrm{mm}$. Hasil rerata daya hambat dapat dilihat dalam garfik berikut:

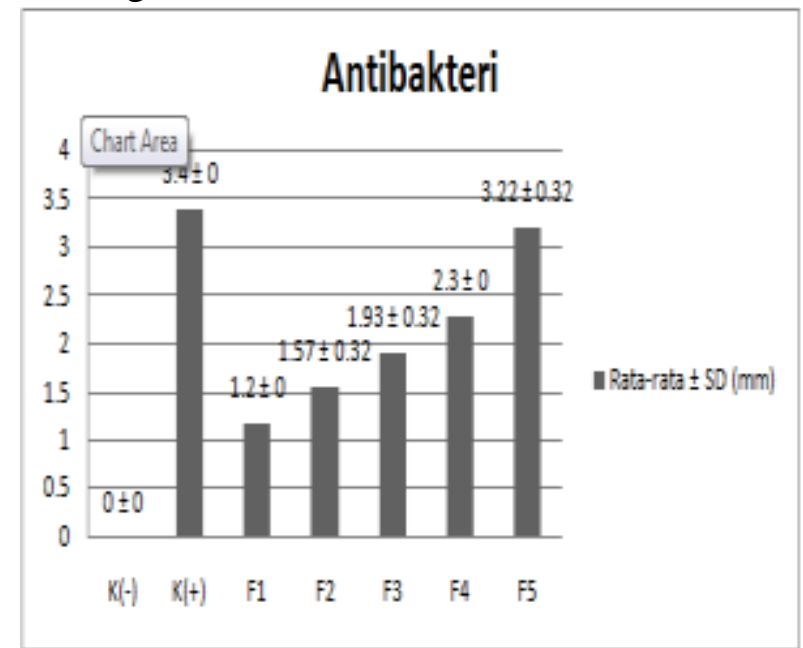

Gambar 1. Hasil uji antibakteri sediaan masker Keterangan : gel peel off esktrak etanol daun alpukat.

K (-) : Kontrol Negatif (Basis Sediaan); K (+) : Kontrol Positif (Gel Spot "Acnes); F1 : Formula 1 Sediaan Masker Gel peel off konsentrasi 0,1\%; F2 : Formula 2 Sediaan Masker Gel peel off konsentrasi 0,15\%; F3 : Formula 3 Sediaan Masker Gel peel off konsentrasi 0,2\%; F4 : Formula 4 Sediaan Masker Gel peel off konsentrasi 0,25\%; F5 : Formula 5 Sediaan Masker Gel peel off konsentrasi 0,3\%.
Hasil dari uji antibakteri terhadap bakteri Staphylococcuss epidermidis menunjukkan bahwa rerata daya hambat tertinggi dari ekstrak etanol daun Alpukat (Persea americana Mill.) yang diformuasikan dalam sediaan masker peel off yaitu pada konsentrasi $0.3 \%$ dengan rerata diameter daya hambat sebesar $3 \mathrm{~mm}$ dan tergolong daya hambat yang lemah.

\section{Evaluasi Sediaan}

\section{Uji Organoleptis}

Dari hasil pengujian organoleptik menunjukkan bahwa sediaan masker gel peel off ekstrak etanol daun Alpukat ber aroma khas daun Alpukat dengan warna hijau pekat dan bentuk semi padat. Tidak ada perubahan pada sebelum dan sesudah cycling test.

\section{Uji pH}

Hasil uji pH didapati hasil sebelum cycling test yaitu 6,11 dan sesudah cycling test pada siklus 1 sampai siklus 6 yaitu sebesar 6,$31 ; 5,74 ; 6,10 ; 6,17 ; 6$ dan 6 . Hal ini menunjukkan bahwa sediaan masker gel peel off ekstrak etanol daun alpukat memenuhi syarat rentang $\mathrm{pH}$ yang dapat diterima oleh kulit yaitu $\mathrm{pH} 4,5$ - 6,5 (Tranggono dan Latifa, 2007). Perubahan nilai $\mathrm{pH}$ dapat menandakan adanya reaksi atau kerusakan komponen penyusun didalam sediaan tersebut sehingga dapat menurunkan atau menaikkan nilai $\mathrm{pH}$ sediaan.

\section{Uji Diameter Daya Sebar}

Daya sebar sediaan masker gel peel off esktrak etanol daun alpukat sebelum cycling test sebesar $6,2 \mathrm{~cm}$ dan sesudah cycling test yaitu sebesar $6.465 ; 6.95 ; 6.45 ; 5.68 ; 6.21$ dan $6.44 \mathrm{~cm}$. Dapat terjadi penurunan daya sebar selama penyimpanan akibat tertahannya cairan pelarut yang diabsorbsi oleh gelling 
agent (Sulastri \& Chaerunisa, 2017). Perbedaan daya sebar masker gel peel off dikarenakan daya sebar berbanding terbalik dengan viskositas.

\section{Uji Daya Lekat}

Hasil pengujian daya lekat pada formula optimum sediaan masker gel peel off ekstrak etanol daun alpukat sebelum cycling test yaitu 22,95 detik dan sesudah cycling test yaitu pada range 20-21 detik. Pengujian daya lekat bertujuan untuk mengetahui kemampuan masker gel peel off melekat pada kulit. Daya melekat sediaan yang baik adalah lebih dari 4 detik (Rachmalia, dkk., 2016). Semakin besar daya lekat maka absorbsinya semakin besar karena ikatan yang terjadi antara masker peel off dengan kulit akan semakin lama. Sediaan yang melekat baik pada kulit akan mengoptimalkan penggunaan pada kulit dan menghindarkan pemakaian berulang. Sediaan mudah lepas dari kulit jika kemampuan melekatnya rendah sehingga efek yang diberikan tidak maksimal.

\section{Uji Waktu Mengering}

Hasil uji waktu mengering sediaan masker gel peel off ekstrak etanol daun alpukat sebelum cycling test yaitu 27,44 menit dan setelah cycling test yaitu dalam range 3059 menit. Pengujian waktu mengering bertujuan untuk mengetahui berapa lama masker gel peel off pada permukaan kulit dan membentuk lapisan film. Syarat waktu mengering yang baik yaitu 15-30 menit (Vieira, 2009).

Penyimpanan sediaan pada saat cycling test meningkatkan kadar air dalam sediaan. Semakin besar konsentrasi PVA, maka semakin cepat kemampuan mengering, hal ini dapat disebabkan oleh banyaknya kandungan air dalam sediaan yang dapat memperlambat penguapan dan pembentukan lapisan film pada masker gel peel off.

\section{Uji Sterilitas}

Hasil uji sterilitas pada sediaan masker gel peel off ekstrak etanol daun Alpukat menunjukkan tidak adanya petumbuhan mikroorganisme. Hal ini menunjukkan sedian masker gel peel off ekstrak etanol daun Alpukat tergolong steril karena tidak ada pertumbuhan mikroorgansme. Uji sterilitas bertujuan untuk mengetahui suatu sediaan steril atau suatu sediaan tersebut harus terbebas dari mikroorganisme (Divadi dan Yuliani, 2015).

\section{KESIMPULAN}

Konsentrasi terbesar ekstrak etanol daun Alpukat (Persea americana Mill.) yang diformulasikan sebagai sediaan Masker Peel Off berdasarkan uji antibakteri terhadap bakteri Staphylococcus epidermidis didapatkan hasil pada konsentrasi $0,3 \%$ dengan rerata diameter zona hambat sebesar $3 \mathrm{~mm}$. Kualitas formula sediaan Masker Gel Peel Off ekstrak etanol Daun Alpukat (Persea americana Mill.) memenuhi parameter uji dari beberapa uji seperti uji $\mathrm{pH}$, uji daya lekat, uji daya sebar dan uji sterilitas serta stabil secara fisik.

\section{SARAN}

Disarankan pada penelitian selanjutnya dilakukan penambahan dosis konsetrasi ekstrak untuk uji antibakteri agar mendapatkan efek yang terbaik untuk antijerawat dan evaluasi fisik yang lain seperti uji Homogenitas, uji Ketebalan Film dan uji Viskositas serta uji Iritasi.

\section{DAFTAR PUSTAKA}

Angela, L. 2012. Aktivitas Antioksidan dan Stabilitas Fisik Gel Anti-Aging yang Mengandung Ekstrak Air Kentang 
Kuning (Solanum tuberosum L.). [skripsi]. FMIPA UI, Depok.

Christianto, C.W., Nurwati, dan D. Istiati. 2012. Efek Antibakteri Ekstrak Biji Alpukat (Persea americana Mill) terhadap pertumbuhan Streptococcus mutans. Oral Biol Dent Journal. 4(2) : 40-44.

Cushnie, T. P and Lamb, A. J. , 2005. Antimicrobial Avtivity of Flavonoids. International Journal of Antimicrobial Agents. Elsevier, UK.

Pardiansyah, R. 2015. Association Between Personal Protective Equipment with the Irritant Contact Dermatitist in Scavengers. Faculty of Medicine Lampung University, Lampung.

Divadi, A., dan S.H. Yuliani. 2015. Pembuatan dan Uji Aktivitas Sediaan Gel Scarless Wound dengan Ekstrak Binahong dan Zat Aktif Piroxicam. Jurnal Farmasi Sains dan Komunitas. 12(2):41-47.

Djajadisastra, J., Mun'im A., dan Dessy N.P. 2009. Formulasi Gel Topikal dari Ekstrak Nerii Folium dalam Sediaan Anti Jerawat. JFI. 4(4): 210-216.

Edy, H.J., Marchaban S., Wahyuno E., dan Nugroho A.E. 2016. Formulasi dan Uji Sterilitas Hidrogel Herbal Ekstrak Etanol Daun Tagetes erecta L. Pharmacon Jurnal Ilmiah Farmasi. 5(2).

Edy, H.J., Marchaban S., Wahyuno E., dan Nugroho A.E. 2017. Formulation and Evaluation of Hydrogel Containing Tagetes erecta L. Leaves Etanolic Extract.
Ortez, J. H. 2005. Disk Diffusion testing in manual of antimicrobial susceptibility testing. Marie B. Coyle (Coord. Ed). American society for Microbiology, America.

Rahmawati, D., Sukmawati, dan A., Indrayudha, P. 2010. Formulasi Krim Minyak Atsiri Rimpang Temu Giring (Curcuma heyneana Val \& Zijp), Uji Sifat Fisik dan Daya Antijamur terhadap Candida albicans secara in vitro. Maj. Obat Tradisional. 15: 56-63.

Rajalakshmi, G. N. 2009. Formulation and Evaluation of Clotrimazole and Ichtammo Ointment. International Journal of Pharma and Bioscience. (4):10-12.

Septiani, S., N. Wathoni, dan S.R. Mita. 2012. Formulasi Sediaan Masker Gel Antioksidan dari Ekstrak Etanol Biji Melinjo (Gnetun gnemon Linn.). Jurnal Penelitian. 1(1).

Sulastri, E., dkk. 2016. Pengaruh Pati Pragelatinasi Beras Hitam Sebagai Bahan Pembentuk Gel Tehadap Mutu Fisik Sediaan Masker Gel Peel Off. Jurnal Pharamascience. 3(2): 69-79.

Tranggono, R.I., dan F. Latifah. 2007. Buku Pegangan Ilmu Pengetahuan Kosmetik. PT. Gramedia, Jakarta.

Vieira, R.P., A.R. Fernandes, T.M. Kaneko, V.O. Consiglieri, C.A.S.O, Pinto. 2009. Physical and Physicochemical Stability Evaluation of Cosmetic Formulations Containing Soybean Extract Fermented by Bifidobacterium animalis. Brazilian Journal of Pharmaceutical Sciences. 45(3): 515-525. 
Yeom, G., D.M. Yun, Y.W. Kang, J.S. Kwan, I.O. Kang, S.Y. Kim,. 2011. Clinical efficacy of facial masks containing yoghurt and Opuntia humifusa Raf. (FYOP). J. cosmet Sci. 62 (5): 505-514.

Yunikasari, D., J. Waluyo, S. Murdiyah. 2016. Uji Daya Hambat Ekstrak Etanol Daun Alpukat (Persea americana 